\title{
PREPARATION AND EVALUATION OF PROPERTIES OF CAST METALLIC FOAMS WITH REGULAR INNER STRUCTURE
}

\begin{abstract}
Lately we encounter still more new applications of metallic foams, as well as possible methods of their manufacture. These metallic materials have specific properties, such as large rigidity at low density, in some cases high thermal conductivity, capability to absorb energy, etc. The work is focused on the preparation of these materials using conventional casting technology, which ensures rapid and economically feasible method for production of shaped components. In the experimental part we studied conditions of casting of metallic foams with a regular structure made of ferrous and non-ferrous alloys. For thus obtained castings we evaluated the achieved microstructure and mechanical properties, which determine the possible use of these materials. The samples were subjected to compression tests, by which we investigated deformation behaviour of selected materials and determined the value of energy absorption.
\end{abstract}

Keywords: metallic foams; casting; microstructure; mechanical properties

\section{Introduction}

The concept of metallic foam is known already for more than 70 years. During this time this special material appeared in many forms and shapes and numerous methods for its manufacture were developed. It also still finds new uses in various industries and in design. This material offers first of all the possibility of reducing the weight of the product with the least possible impact on its strength. The weight reduction is achieved by deliberate creation of pores, bubbles, voids or holes in the material. These cavities may have different distribution - regular or irregular. They may have a structure with open pores (that are mutually interconnected) or with closed pores (separated from each other). It is possible to create just porous metal or metallic foam with a solid surface crust. Metallic foams can be made from many alloys, such as alloys of $\mathrm{Al}, \mathrm{Cu}, \mathrm{Mg}, \mathrm{Zn}, \mathrm{Pb}, \mathrm{Ti}, \mathrm{Fe}, \mathrm{Ni}$ [1-3].

\section{Properties and utilization of metallic foams}

This material offers the particularly the following most important properties:

- Reduction of mass: porous metals are very light and it is possible to achieve very high strength by application of ribbing.

- Absorption (damping) of energy: it uses ability of this type of material to get deformed under pressure and absorb in comparatively small volume big amounts of energy. This property can be used in transport industry for deformation zones of vehicles.

- Absorption (damping) of sound and vibrations: replacement of organic foam material in environment with extreme thermal and mechanical loads.

- Thermal stability: metallic porous materials preserve high mechanical properties even at high-temperatures.

- Heat transfer: metallic porous materials with open structure have large specific surface, which gives them better abilities of heat exchange $[4,5]$.

\section{Methods for manufacture of metallic foams}

Since the discovery of porous metallic materials numerous methods for their production were developed. Some technologies are similar to those used for the manufacture of polymeric foams, and others are developed with respect to the characteristic properties of metallic materials. According to the state, in which the metal is processed, it is possible to divide the manufacturing processes into four groups. The porous metallic materials may be made from $[1,5]$ :

- Molten metal (e.g. direct foaming of molten metal, foaming agents, casting, etc.);

- Powder metal (e.g. sintering of powders, fibres or hollow balls, reactive sintering); 
- Metallic vapours (vapour deposition);

- Metallic ions (electrochemical deposition).

Porosity can reach $30 \%$ up to $93 \%$, depending on the manufacturing method and the material used. By changing the parameters of the manufacturing process it is possible to obtain a porous structure with different pore sizes and shapes and with different types of arrangements (regular or stochastic) [4,5]

\section{Use of a preform as the core}

Infiltration of metal into the mould is made by pouring of liquid metal into the mould filled with inorganic or organic particles, so called precursors or preform. The regular structure of pores, we are dealing with, can be achieved by use of various types of semis, which fill the mould cavity. The preform with cellular structure can be used as a core (Fig. 1) and it is thus possible to create castings with strong surface layer and internal porous structure (Figs. 2,3).

The preform must meet certain criteria. Particularly, it must be made of material, which preserves its shape at impact of the molten metal (sufficient strength, low abrasion, heat-resistance) and it must allow also good disintegration after casting [5].

In the experiment castings with regular cellular structure with use of sand core were made. Manufacture of core box for production of cores by PUR Cold box technology followed by casting of the primary castings was performed in collaboration with the foundry and pattern shop Nové Ransko. Core of the casting was composed of six parts and it was put into a core print.

The casting was machined from all its sides in order to ensure an exact seating of the pressing head at the following compression test. Dimensions of the sample were $63 \times 65 \times 90 \mathrm{~mm}$ and its porosity was calculated to be $50 \%$.

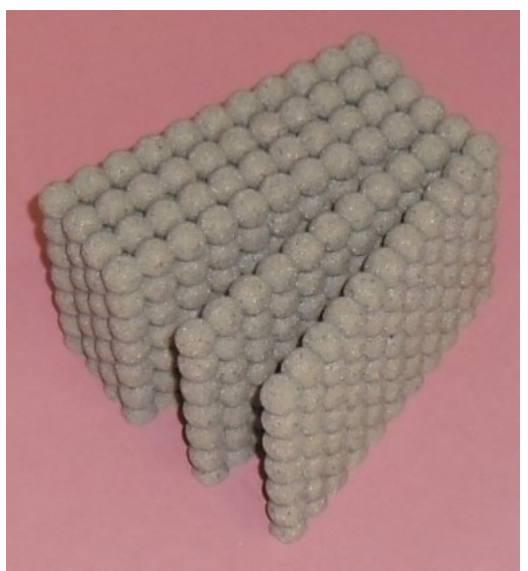

Fig. 1. Preform with cellular structure

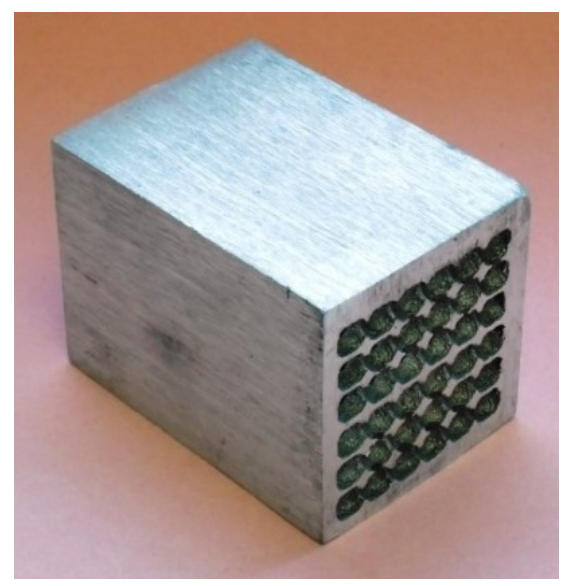

Fig. 2. Metallic foam with regular structure [6]

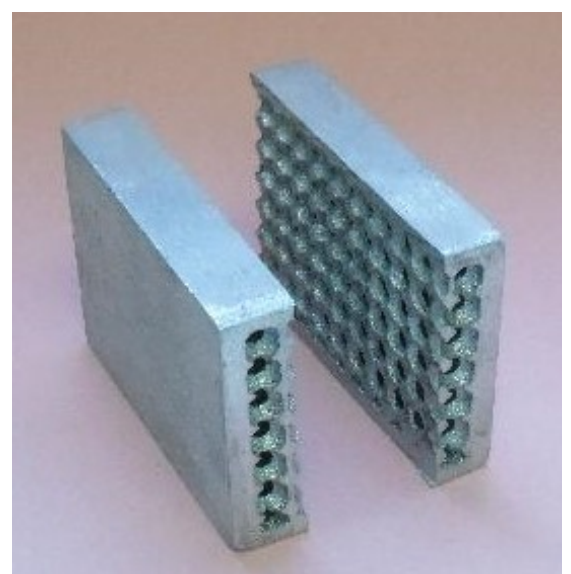

Fig. 3. Metallic foam (transection)

\section{Samples for compression test}

TABLE 1

Metallic foams were prepared by using gravity casting to sand mould. Cast materials were non-ferrous alloys (CuSn10, AlSi10MgMn) and cast iron with lamellar graphite (EN-GJL-200). Castings of metallic foams were cut to samples with dimension $65(\mathrm{H}) \times 30(\mathrm{D}) \times 45(\mathrm{~W}) \mathrm{mm}$ (Fig. 4). Results of achieved density and porosity of prepared samples are shown in the Tab. 1 .

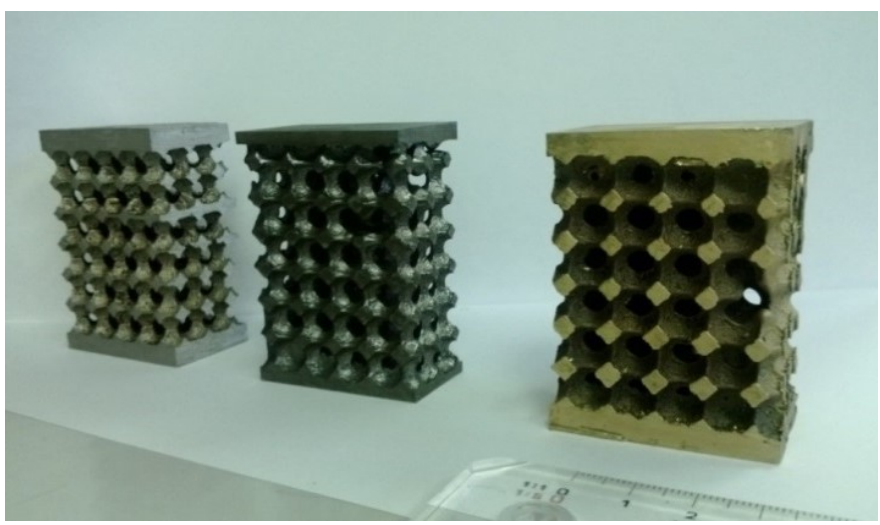

Fig. 4. Prepared samples for compression test

Example of achieved of material's density and porosity

\begin{tabular}{|c|c|c|}
\hline \hline Material of metallic foam & Density [kg/m $\mathbf{m}^{\mathbf{3}}$ ] & Porosity [\%] \\
\hline $\mathrm{CuSn} 10$ & 3935 & 55 \\
\hline AlSi10MgMn & 1217 & 55 \\
\hline EN-GJL-200 & 3217 & 55 \\
\hline
\end{tabular}

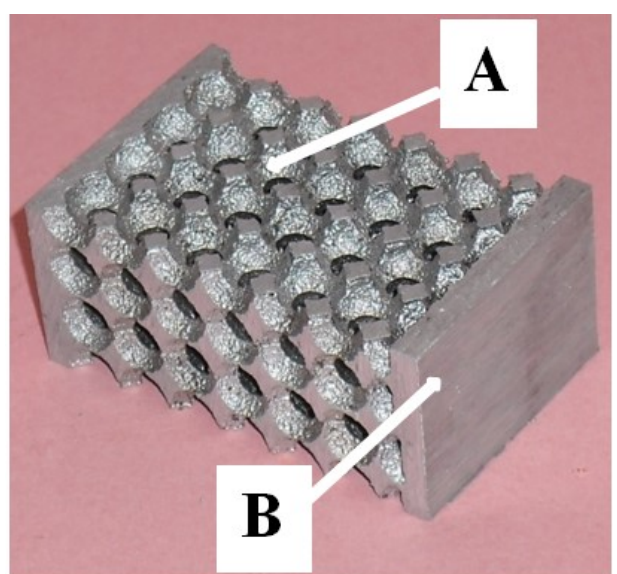

Fig. 5. Sample for evaluation of microstructure [6] 
For the evaluation of microstructure of the sample was selected part from the central point of the casting (A), which has been in contact with the material of the core, and the part of the surface (B), which has been in contact with the material of the mould (Fig. 5).

The microstructure of surface part (B) of the sample (AlSil0MgMn) is shown on the Fig. 6. On the Fig. 7 we can see the microstructure of the central part (A) of the same sample. From the figures, it is evident that it is alloy with eutectic composition. In the structure it is possible to identify the $\alpha$-phase (Al) and $\beta$-phase ( $\mathrm{Si}$ ). In the case of microstructure of the sample's surface, we can observe a significantly smaller size structural

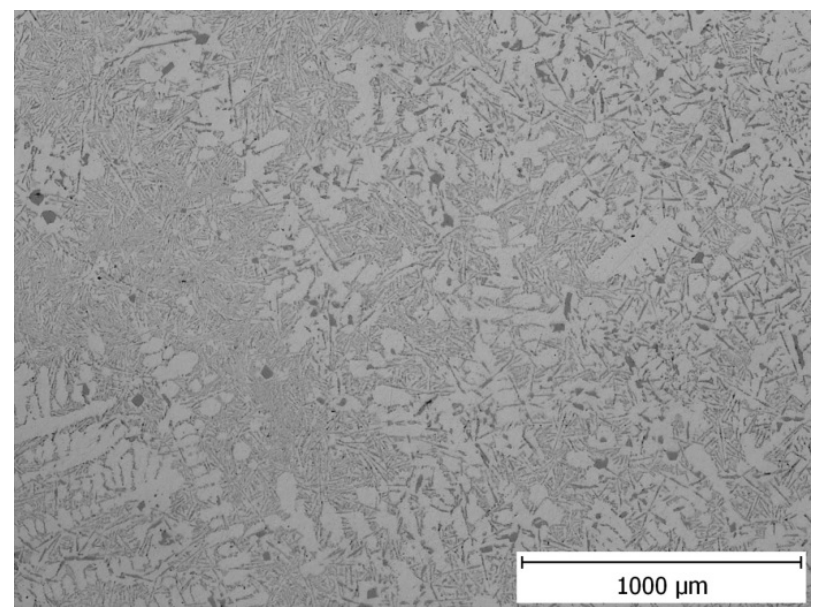

Fig. 6. The microstructure of surface part of the sample (AlSi10MgMn)

\section{Results and discussion}

The compression test was performed in order to verify the ability of porous material to absorb energy by deformation. Material's ability to absorb energy can be determined by evaluating the relation between load and deformation. Calculation component compared to the microstructure of the central part of the sample. This phenomenon is associated with different cooling effect of the mould (on the surface) and the core (the central part).

\section{Compression test and calculation of strain energy}

Prepared samples were tested by compression on the hydraulic testing machine Zwick Z600 with the maximum compressive force of $600 \mathrm{kN}$ and the feed rate of the crossbeam of $10 \mathrm{~mm}$ per minute. This equipment is located in the testing centre of the company Vitkovice Steel.

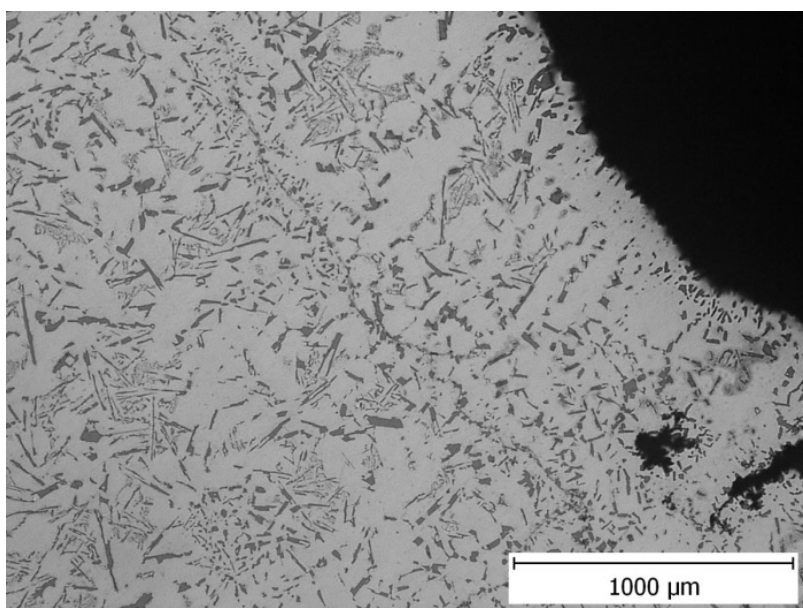

Fig. 7. The microstructure of the central part of the sample (AlSi10MgMn)

of the deformation energy is made from the total surface under the load-deformation curve. The data for the determination are obtained from the measuring instrument for compression testing.

Results of compression test are shown on the Fig. 8. In the Table 2 we can see results of the calculation of load-deformation curve. The maximum deformation energy was achieved by the

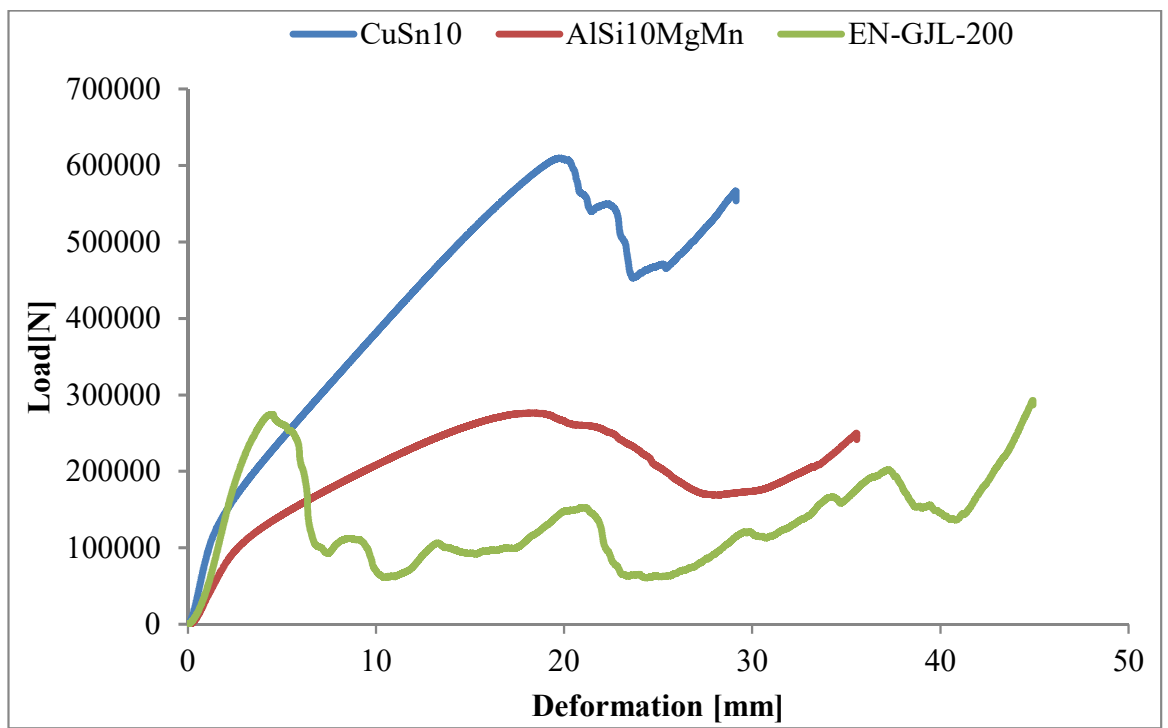

Fig. 8. Results of compression test 
non-ferrous alloy based on copper with addition of tin ( $\mathrm{CuSn} 10)$. In this case the deformation energy achieved $10200 \mathrm{~J}$. Minimum value, $3500 \mathrm{~J}$, of deformation energy was obtain for sample prepared from cast iron (EN-GJL-200).

TABLE 2

Results of the calculation of deformation energy

\begin{tabular}{|c|c|}
\hline \hline Material of metallic foam & Deformation energy $\mathbf{W}[\mathbf{J}]$ \\
\hline CuSn10 & 10200 \\
\hline AlSi10MgMn & 5580 \\
\hline EN-GJL-200 & 3500 \\
\hline
\end{tabular}

\section{Conclusions}

The work was focused on the preparation of metallic foams using conventional casting technology. In the experimental part we studied conditions of casting of metallic foams with a regular structure made of ferrous and non-ferrous alloys. For thus obtained castings we evaluated the achieved microstructure and mechanical properties, which determine the possible use of these materials. The samples were subjected to compression tests, by which we investigated deformation behaviour of selected materials and determined the value of energy absorption.

Out of the three tested materials, the best absorption of energy was achieved by the sample made of the alloy $\mathrm{CuSn} 10$, in which the work of deformation energy exceeded $10000 \mathrm{~J}$. Considerable disadvantage of this material is, however, its high specific density. The alloy AlSi10MgMn also gave interesting results, where the work of deformation energy exceeded $5500 \mathrm{~J}$, while specific density of this alloy achieves almost one-third of that of the alloy $\mathrm{CuSn} 10$.

The selection of the studied materials was based on a comparison of various alloys to assess the appropriate methodology for the practical use of metallic foams in terms of energy absorption. The chosen method is sensitive to the chemical composition of the material and will be used in further experiments to address specific requirements of the designers.

\section{Acknowledgement}

This work was elaborated within the research project TA02011333 supported by the Technology Agency of the Czech Republic and was carried out in the support of projects of "Student Grant Competition" numbers SP2016/89 and SP2016/10.

\section{REFERENCES}

[1] J. Banhart, Production Methods for Metallic Foams. Metal Foams 1998. Verlag MIT, Bremen, 3-12 (1998).

[2] M. Nowak, Z. Nowak, R.B. Pechierski, M. Potoczek, R.E. Śliwa, On the reconstruction method of ceramic foam structures and the methodology of young modulus determination. Archives of Metallurgy and Materials 58, 1219-1222 (2013).

[3] Y. Schmitt, J.L. Pierrot, J.Arbaoui, F.X. Royer, Mechanical properties of a cellular composite: comparision with other structures. Archives of Metallurgy and Materials 50, 111-117 (2005).

[4] J. Banhart, Manufacturing routes for metallic foams. Journal of Minerals, Metals and Materials 52, 12, 22-27 (2000).

[5] J. Banhart, Manufacture, characterisation and application of cellular metals and metal foams. Progress in Materials Science 46, 559-632 (2001).

[6] F. Radkovský, V. Bednářová, P. Lichý, T. Elbel, I. Kroupová, Metallurgy for evaluation of metallic foams. In METAL 2014: 23th International Conference on Metallurgy and Materials: conference proceedings: May 21-23 2014, Hotel Voronez I, Brno, Czech Republic, EU [CD-ROM]. ISBN 978-80-87294-52-9. 